\title{
META - ANALYSIS FOR AGRICULTURAL RESEARCHES (REVIEW)
}

\author{
Eskander H.Ali ${ }^{1} \quad$ Muna A.bulqader ${ }^{2}$ Sura S.Abd ${ }^{3}$
}

${ }^{1}$ Dept. of Agricultural Economics, Colle. of Agricultural Engineering Sciences, University of Baghdad

${ }^{2,3}$ Dept. of Agricultural Economics, Colle. of Agriculture and Forestry, University of

Mosul/ Iraq

Email: eskanderhali81@gmail.com

\begin{abstract}
This article aimed to discuss the Meta- analysis and its use in agricultural research. This analysis carefully reviews the results that have already been published; it works on organizing, integrating and scientific evaluation of previous researches and studies on a specific topic. It is also a statistical analytical approach aimed at interpreting the results of researches collected from multiple studies, it helps in making decisions, and its purpose is statistical integration between the results taken from a large community through several researches on different samples derived from the same community. It is a well-established technique in the natural, medical and psychological sciences, and it was used recently in the field of economics. It is a technique that differs from others; it has its methods, steps and quantitative procedures. Recently, Meta-analysis was considered one of the objective and solid methods in agriculture. Although in cross-sectional agricultural researches there are difficulties due to different conditions and environments, yet Meta- Analysis has become an inevitable method, as it can serve as a summary or a base for data and results that help researchers and determine their research path and direction. It helps decision makers and policy makers as it puts in their hands a large number of results and conclusions.
\end{abstract}

Keywords: Literature review, agronomy, Glass method, effect size Received: 9/8/2020, Accepted: 11/10/2020

\section{INTRODUCTION}

There are many studies and methods in which deficiencies in certain aspects emerged, so in 1976, Glass proposed a new approach that deals with deficiencies of previous methods namely Meta-Analysis, whose roots go back to the seventeenth century $\mathrm{AD}$ when astronomers saw that mixing data may be better than trying to choose from them, also the first medical research in 1904 used formal techniques to collect data from various studies when examining the protective effect of vaccines against enteric fever. And also among the first people to whom the ideas of this analysis come back is the scientist Pearson who conducted a statistical combination of 11 studies on typhoid disease. After that, Fisher came to present a technique in which he tried to incorporate the values of $\mathrm{P}$ that come from statistically independent studies that undergo the same conditions, and then Rubin and Rosental (1990) reviewed 345 studies that deal with the effect of personal harmony on behavior. The psychologist Glass was the first to coin the term Meta-Analysis in his article entitled (Primary, Secondary, and Meta-Analysis of Researches); he reviewed 725 evaluations of the relationship. All these efforts led to the adoption of quantitative procedures for combining research findings (Cooper et al.,2000). Among the reasons that led to the 
emergence of Meta-Analysis is the lack of consistency in many cases among the results of studies, and the difficulty of getting a general conclusion out of them. Although (Jackson;1984) had sent a questionnaire form to 150 well-known authors during the period 1980-1984 asking about how much they know of Meta- Analysis, it turned out that only $15 \%$ of the respondents answered that it was a familiar analysis, and this indicates that most sociologists do not have enough deep understanding of what is Meta- Analysis.

Meta-Analysis means to re-analyze the results of the primary or secondary analysis from the sum of individual researches and studies (Glass et al.,1982). This analysis aims at carefully reviewing the results already published; it is based on organization, integration and scientific evaluation of previous researches and studies on a specific topic, and this is done through specific problem for each study, by clarifying it, and making a brief survey of it to make the reader aware of the current situation of the phenomenon under review, it also points out the relations, discrepancies, inconsistencies, flaws and scientific mistakes in it, as well as assuming suggesting mechanisms that can be referred to, to address these mistakes (Raja,2004). Reviewing literature contributes to the development of sciences, it summarizes our whereabouts; where we were and where we are now, and it determines the need to go forward as well as the gaps in our knowledge, and points out new research trends to be pursued in the future (Gozzo et al.,1987). Drowns (1991) defines it as a set of organized procedures for the inconsistencies that are evident in the results of different researches, Meta-Analysis attempts to review a number of different studies using statistical methods to clarify the relationship between the characteristics of these studies. Others define it as an introduction to the synthesis of research findings. Youssef (1993) sees it as a statistical analytical approach that aims to explain the results of researches collected from multiple studies, and interested in reaching decisions about a number of these researches (quantitative, regulatory, previous researched,conclusions). Hence, Meta- Analysis is a statistical analysis of a large group of detailed research results on a specific topic, and its purpose is statistical integration between the results taken from a large community using several studies on different samples derived from the same community. It is a methodology as it belongs to evidence- based practical methods (Hjorland, 2002), and this was confirmed by (Moirrison,2006) who believed that meta- analysis is one of the evidence- based science activities, and that there is a controversial relation between it and the open access. It is a well-established technique in natural and medical sciences, especially in the case of comparative analysis of near-convergent experiments (Hedges and Olkin, 1985), and recently it has been used in economics as well (Matarazzo and Nijkamp, 1997). It was also used in ecology as it provides statistical techniques increasingly used in ecology (Hedges et al., 1999), in addition to its increasing uses in in the social and applied sciences (Faraj, 2002). It is designed to deal with a large amount of studies (Anna and Daniel,2006 and corinee and Byrun, 2013), not to mention its dealing with comparisons between pairs of interference which link three interferences or more through direct and non- direct comparison, through a net of interferences in one analysis which is called net meta- analysis (Chaimani et al., 2013).

Many researchers, when conducting their research, focus on statistical significance in accepting or rejecting the research hypothesis, and this makes them commit two 
mistakes; the first is called the alpha error resulting from admitting the existence of an impact, although it is not present, and the second is called the beta error that arises from the dependence of the significance on the sample size; using meta- analysis and effect size lessen the error rate and coincidence factor generated as a result of depending on statistical significance and measurement tools, design issues and choice of sample can be added (Al-Zaid, 2015). This is consistent with the American Psychological Association's recent publication indicating that most studies rely heavily on statistical significance, which is only a starting point, and that it needs other elements such as effect size, confidence intervals, description, and depth to reach a more complete meaning of results hence, meta-analysis works on solving problems or at least interpreting them (Al-Juhny, 2017).

Meta-analysis approaches survey studies in many of their characteristics and differs from them in that survey studies lack the possibility of reaching the third variable in research, which is the causal relationship between independent and dependent variables, it is an organized statistical quantitative method to organize, derive and examine information from a large amount of data and results that help reaching a general conclusion regarding the effectiveness of these researches, and then making it possible to make a specific decision in adopting the results of these researches (Hassan,2005). This analysis also helps determining the need for further studies and researches in a specific field, as well as examining the reliability of theories presented in light of its findings using different samples (Carson et al.,1990). It is a verification of the facts (Cook and Leviton, 1980), determination of facts in literary reviews, and discovery of underlying relationship patterns which contributes to the formation of cumulative knowledge (Hunter et al.,1982). Winston (2007) sees that this analysis goes beyond statistical or quantitative data to include information related to the design, methodology, approaches and environment of the research. MetaAnalysis is an approach different from other approaches used to combine studies; they randomly excludes master's theses and doctoral dissertations being unpublished studies, as well as a number of researches due to their weakness resulted from tools, measurement, design, and description. Meta-Analysis, on the other hand, does not exclude any study and its judgments are post rather than being pre- judgments. There are different perspectives on Meta-Analysis; some see it as a complete research methodology, based on the results of Meta-Analysis being the results of the study, thus, it occupies the same position of other research methods such as the experimental approach and others. Some classify it as a statistical analysis as it relies on statistical methods and tools that deal with the results of the collected studies, and this perception fits its nature being a quantitative method in the first place. Others see that MetaAnalysis is a review of the previous literature and this is consistent with Glass, who considers Meta-Analysis as an organized means to review past literature, distinct from the traditional descriptive methods of review (Salim and Al-Mutairi, 2005). Those who deal with and apply Meta-Analysis must have some skills, including awareness of the most important matrices and sources of information, skills of using scientific research centers and electronic information sources of research and some skills of quantitative methods. The main goal of Meta-Analysis is to determine a summary of the effect size, which is a measure of the strength of the relationship between variables and their orientations by collecting data from multiple studies (Çoğaltay and Karadağ , 2015). 
Therefore, it is an approach that does not differ from other scientific research methods in terms of identifying the problem, forming hypotheses and goals, determining and measuring variables, and choosing the sample; it is a complete method, restorable and repeatable (Abu Hatab and Amal,1991).

Meta- analysis remains like any other approach that has some defects, including selecting only a subset of studies and this leads to bias, ignoring the random sampling mistake, also ignoring information about the size of the relationship between variables and focusing on whether the hypothesis is statistically proven or not, ignoring the potential effects of the characteristics of the study on the interrelationships between the variables, in addition to having self-defined procedures that impair the review, having in mind that these defects can be addressed by several procedures, such as conducting a comprehensive review, focusing on studies related to the subject of the review, and adopting procedures for Meta-Analysis such as determining the amount of variance. There is a possibility of using many quantitative methods to overcome problems that may arise when applying this analysis (Gozza,2012). The possibility of conducting meta- analysis depends heavily in recording results on the extent of consistency between previous studies (Saxton, 2008).

\section{Methods of Meta- Analysis:}

There are several methods of Meta- Analysis, including:-

- Glass Method: In this method, all studies on the subject or problem to be studied are collected, including studies and researches that contain inadequate research methods and approaches, or do not match the known methods and approaches, then the results of these studies are converted into a common unit of measurement, and comparisons can be made after dividing them into groups and taking a result from each study.

- Mansfield and Busse method: Criticisms were addressed to Glass method, the most important of which is that the study is represented more than once resulting in a large number, and the problem increases if the studies were divided into a specific classification, so this method came to address this problem by relying on the size of one effect for each study, and in the event that there is more than one scale for the dependent variable, the effect sizes can be added or the weighted average can be found for these sizes if the scales were measuring the same variable, but if there were more than one variable, a number of Meta- Analyses is performed according to the number of variables (Hassan, 2005).

- Stouffer Method. This method depends on the statistical significance of the hypothesis for each study, and it depends on the collection of $\mathrm{Z}$ degrees and their division by the square root of the total studies included in the analysis, and then finding the total level of significance. Here, it is preferable to use at least 34 studies (Cooper, 1979).

- Hedges and Olkin method: This method emphasizes the homogeneity among the variables included in the analysis before their collection, and it is not different from other methods with regard to the size of the effect, but it emphasizes the homogeneity of these sizes, and this can be verified using Q-Statistic (Mansfield and Busse,1977; and Hassan,2005).

- Hulter and Sehmidt Method: Here the effect size is calculated for each study and then these sizes are collected and errors associated with the sample and the measurement method are excluded, and if it appears after this exclusion and correction 
that the size of variation is large, then this indicates the existence of intermediate variables that explain the size of the variation. Some believe that this method is the same as the Glass method Plus some improvements and modifications.

Basic Steps for Meta-Analysis (Moher et al.,2015; Gozza et al., 2012; Jerry and. Shelby , 2008)

- Interpreting the concept of the problem and the effectiveness of the hypothesis.

- Determining of the variables of importance and influence, and emphasizing the study of the causal relationship between the variables.

- Data collection and processing.

- Determining the location for collecting studies.

-Assessing the efficacy of the studies.

-Assigning a code for each study or group.

-Analyses.

- Entry of results.

\section{Meta- Analysis in agronomic researches:}

In 2010, Dore recommended that agricultural researchers conduct meta-analysis to investigate patterns in crop system performance, and more than 1,000 studies in agriculture using meta- analysis have been published since 1985. Fisher (2015) considers meta- analysis to be an objective and solid methods in the field of agriculture. Although in cross-sectional researches it is sometimes difficult to apply this analysis due to regional differences, climate, soil and agricultural practices that make it inevitable to face some differences in experimental methods and objectives, however, meta-analysis techniques remain perfectly suitable to deal with them as explanatory variables when data is taken through researches that apply consistent definitions, units and treatments, and actual results can be determined by more realistic forms of tables, in a way that it is difficult to extract accurate values for modeling or meta- analysis, because factors are related to the location and therefore estimates must be taken from large samples because their potentials are more reliable than those taken from small samples, because the economic theory tells us that the variance in these samples is smaller (Shaddish and Haddock,1994), and it is more convenient when the studies are small and their results are controversial (Gogtary and thatte , 2017), small sample size can be overcome in individual studies in addition to generating new assumptions or shedding light on research problems of future studies, and that metaanalysis expands the potential effect of the primary research studies through putting them as essential contributions within the larger image of the research subject (Gerstner et al.,2017). ANOVA analysis can solve the complexity since no errors are recorded on it, but the difficulty of determining suitable weights remains. Also the lack of data and the differences in the sectional ones make the descriptive studies a great opportunity in meta-analysis, as the treatment of data restrictions by contacting some authors, although it may constitute an unnecessary burden. For example, few studies reported fertilizers losses of $\mathrm{N}$ and $\mathrm{P}$ elements but they did not report different nutrient loss pathways (Alison,2017). While a few studies reported NO2 and NO3 losses, which makes it difficult to exchange between these two tracks of environmentally sensitive loss. Whereas we note that there are more than 54 studies that dealt with nitrogen fertilizers before planting. 
The concept of yield stability in plant growing has developed, however, in recent years it received an increasing attention from scientists of environment (Lin and Lefkovitch, 1986), especially regarding the stability of the ecological system work (Tilman et al.,2006; and Oltmer et al., 2000) used meta- analysis to assess the effects of agricultural environmental policies in the European Union. This effect was through nitrogen fertilizers, livestock and pasture area. The study included 22 fields, 2 fields in each country except Sweden where 4 fields were chosen. The study included 1000 farmers; 25 in each study area ( 25 farmers in the case of Sweden). The researcher used ANOVA analysis, Effect Size, Q-W ithn statistic, correlation coefficient and mean absolute value.

Coca (2017) evaluated innovation in agriculture through an analytical study of information taken from a wide range of studies and researches published in this field using the meta- analysis approach from a methodological point of view including rules for choosing databases on the Internet, areas of interest and determining the level of analysis and combining concepts of analysis, then analysing data. 454 studies for the period 1990-2015 were used, and 60\% of them were published after 2010, this indicates the growing importance of the topic.

Alison et al .,(2017) )conducted a meta- analysis on the effect of water and air on nutrition management practices and nutrition research, in which they emphasized that agricultural environmental dimensional analysis reduces data defects and promotes consistency between studies, and this research recommended improvements in the design of field research and data collection, and the preparation of reports to improve the synthesis of environmental agricultural data.

Knapp et al., (2018) used meta- analysis to assess the stability of the annual productivity of three main agricultural systems namely organic agriculture, agriculture without tillage and conventional agriculture, they reviewed 193 studies based on 2896 comparisons, and used REML, the variance matrix and the relative and absolute stability ratio to calculate the difference between these studies. (Lauren et al , 2015; Pittelkow et al .,2015; De Ponti et al .2012 and Seufert et al .,2012) interfered with them and performed two-dimensional comparisons also for comparison between these systems for 1071 instances, and they emphasized that organic cultivation has an average yield of $19.2 \%$ more than conventional cultivation, and that no-till reduces productivity by $5.7 \%$ compared to conventional tillage, and the effects were variable depending on the type of crop, also the relative stability of organic farming was less than that of conventional agriculture, and absolute stability has not differed between the two systems. Also, Sacha and Bilton, in 2018, applied meta- analysis for studies dealing with the adoption of agricultural techniques in developing countries. A research report on climate change, agriculture, and food security was recently issued by the Consultative Group for Agricultural Research (CGIAR); it dealt with the metaanalysis of the response of agricultural crops to organic farming in the desert of Africa. They used the help of experts from CA, SSA, and multiple research results were collected and a comparison was made to know the effects of tillage and crop remains management on crop productivity, in SSA. 120 studies were reviewed, 49 of them in Africa, and 20 other studies on conservation agriculture, and the data covered 61 locations. 
Timothy and Andersson , (2019) applied meta- analysis to answer the question of whether size has an effect in agronomy. The study included researches published since 2007, and was comprehensive but focused on modern ones, summarized 77 studies and reviewed new perspectives through looking in researchers' methods within the framework of analytical research questions. Ali et al.,(2020) resorted to meta-analysis as they conducted an economic analysis of the factors affecting farmers' decisions of the use of chemical fertilizers in Iraq; they reviewed 18 studies and researches to find out the costs of chemical fertilizers per dunum and the revenues and profits of those crops, 6 studies on the size of surplus and deficit in the amount of chemical fertilizer using the data envelope analysis method DEA, and 8 studies to know the fertilizer parameter as an independent variable in the production functions and its effect on the production of some crops. The Technical University in Denmark DTU conducted meta-analysis of the effects of the productivity of nested cereal crops, and reviewed the researches within the university's database since 1900. This included 204 research papers, and they collected other data on fertilizer, seed density and soil type. A set of analytical tools were used, including the LER, Caps Function, Covari- ance, links matrix, and random and fixed effects models.

The Florida Department of Agriculture and Consumer Services (FDACS), Office of Agricultural Water Policy (OAWP), set a strategic objective to develop and implement best management practices (BMPS) and consolidate their effectiveness; it contracted with Frydenborg Ecologic to conduct a meta-analysis to determine an activity to reduce pollution in the state of Florida. 1000 articles were reviewed resulting in 267 articles containing information on management practices of agriculture in Florida, including three groups, the first (sorghum, andropogum sorghum, peanuts, cotton, sugar cane), the second (potato, strawberry, tomato, cucumber, pepper, watermelon) and the third (cows). The study applied a set of tools for meta- analysis, including the effect size, ML model, frequency and variance equal 0.(Bill and Russal,2010)

Agricultural scientists and researchers are always required to continuously and increasingly address the challenges related to natural and productive resources, the optimal use of resources and environmental protection, and taking into account the effects and risks related to climate and their forecasting; this represents a challenge when using traditional methods of data management, and to address this challenge correctly it is necessary to provide multiple data, and it is also necessary to follow a new and good directed approach to overcome the problems and to move towards transformational science (Herzmann et al., 2014; and Hunt et al.,2001).

Thus, meta- analysis will be a basis that can be resorted to in all reviews. It can serve as a summary or a base for data and results that help researchers and determine their path and research direction, it helps decision makers and policy makers as it puts in their hands a large number of results and conclusions. This analysis also helps researchers and post - graduate students in identifying solid researches, and can give them answers regarding whether this subject need other studies or not. Especially in agricultural researches that are affected by the conditions, environment and region, as well as the opinions of researchers. In addition to that, agricultural researches, especially those related to the agricultural economy, is carried out on one crop and one 
region and this analysis can cover a large group of research that can summarize our whereabouts; where we were and where we are now and define the need to go forward.

\title{
التحليل البعدي واستخدامه في البحوث الزراعية
}

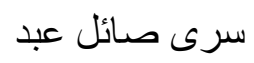

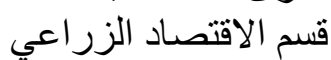 \\ كلية الزر اعة والغابات/موصل الزئل
منى عبد القادر احمد

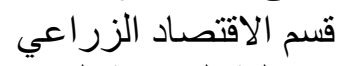
كلية الزر اعة الغاباتت /موصل
اسكندر حسين علي الزماد اعي الزي \\ قسم الاقتصاد الزر اعي اعي \\ كلية علوم الهندسة الزر اعية/جامعة بغداد الزية
}

\section{الخلاصة}

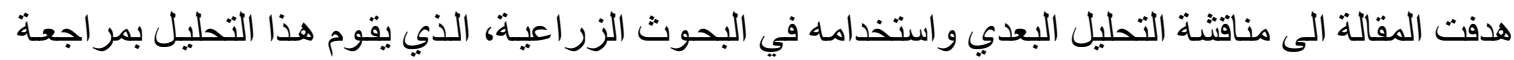

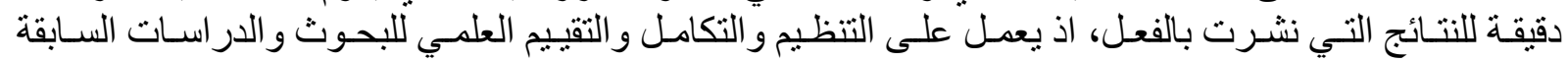

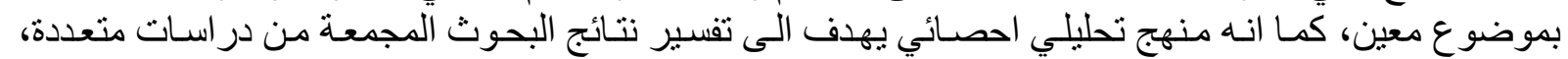

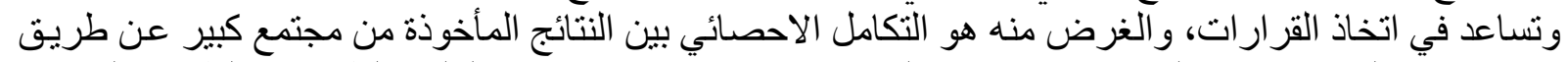

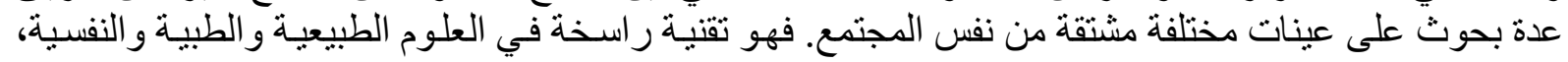

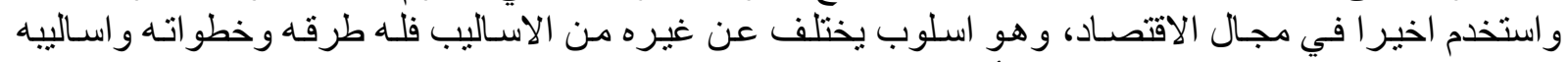

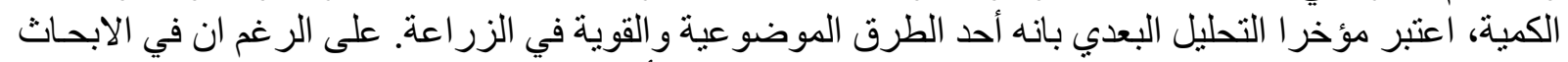

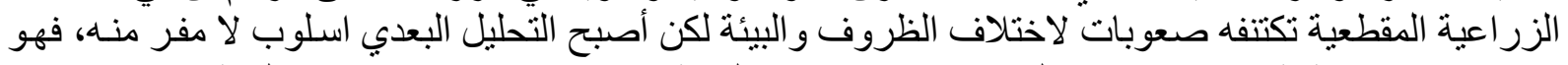

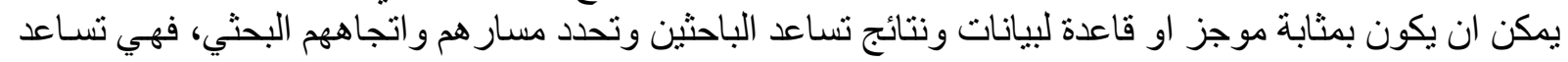

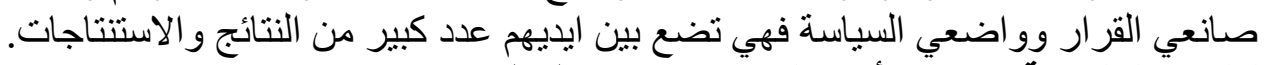

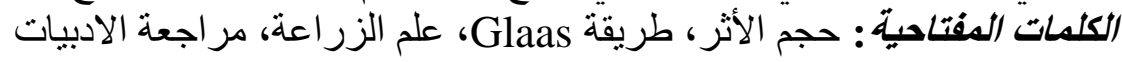

تاريخ تسليم البحث: 2020/8/9، وقبوله: 2020/10 /

\section{REFERENCES}

Abu Hatab, F. and S. Amal. (1991). Statistical Analysis Methods in Psychological, Educational and Social Sciences. Cairo, pp834.

Al- Juhny, L. S. (2017). The efficacy of e- learning in light of meta- analysis results of published studies in some arabic periodicals from 2005-2015. the specialized international educational journal, 6 (7), 15-33.

Al- Zaid, J. M.. (2015). Meta- Analysis and Effect Size. Studies of Development, Research and Sciences and Mathematic Teaching Center. pp 1-17.

Ali E. H., A. ALsaad and S. Abd. (2020). An economic analysis of factors affecting farmer's decision on using chemical fertilizers. International journal of agricultural and statistical sciences.16(281-288)

Alison J. E,E.C. Laura,L.C. Rachel, R. D. Harmel, E. M. Fernando, S. S. Qian, and A.R.Dorivar. (2017). Meta-Analysis Constrained by Data: Recommendations to improve relevance of nutrient management research. agronomy journal.109(6):2441-2449.

Anaa, M. and V. Daniele.(2006). Fertility And Women's Employment A MetaAnalysis. Mpidr Working Paper.PP:25. 
Biehl, D. (1999). Agri-environmental policies in a wider theoretical and institutional context. Journal of rural studies (16)1: 285-294.

Bill, B.,R. Beck. and B. Russel. (2016). A Meta-Analytical Approach for Determining the Effectiveness of Agricultural Best Management Practices (BMPs) for Reducing Nutrient Pollution in Florida. A Systematic Review of BMP Effectiveness.USA.PP:98.

Carson, K., C. Schriesheim and A. Kinicki. (1990).The Usefulness of the Fall - Safe statistic in meta . analysis. Educational and Psychological measurement. 50(2):233-243. https://doi.org/10.1177\%2F0013164490502001

CCAFS. (2014). Meta-analysis of crop responses to conservation agriculture in subSaharan Africa. CGIAR Research Program on Climate Change Agriculture and Food Security. Report No. 12.pp:20. https://ccafs.cgiar.org/ publications/ meta-analysis-crop-responses-conservation-agriculture-sub-saharan africa \#. $\underline{\mathrm{X} 2 \mathrm{eDpPnXLIU}}$

Chaimani A, J.P. Higgins,D. Mavridis,P. Spyridonos and G .Salanti. (2013). Graphical tools for network meta-analysis in STATA. :1-12. https://journals.plos.org/ plosone/article?id=10.1371/journal.pone.0076654.

Coca, O. (2017). The evaluation of innovation in agriculture. a meta -analytical study of literature. scientific papers series management, Economic Engineering in Agriculture and Rural development. 17(1):111-120.

Çoğaltay, N., and E. Karadağ. (2015). Introduction to Meta-Analysis. In Leadership and Organizational Outcomes. Springer International Publishing.USA. (pp. 19-28).

Cook, T.D., and L.C. Leviton. (1980). Reviewing the literature: A comparison of traditional methods with meta-analysis. Journal of Personality, 48, 449-472.

Cooper, H. (2000). Statistically combining independent studies: A meta- analysis of sex differences in conformity research. Journal of personality and social psychology .37(1):131-146

Corinne P. and K. Byron.2013. Women on Boards and Firm Financial Performance: A Meta-Analysis. Academy of Management Journal.58(5):56-63.

De Ponti, T.B Rijk, and M.K. Ittersum. (2012). The Crop Yield Gap Between Organic And Conventional Agriculture. Agricultural Systems. 108, 1-9. https://doi. org/10.1016/j.agsy.2011.12.004

Doré, T., D. Makowski, E. Malézieux, J. Munier and P. Tittonell (2011). Facing up to the paradigm of ecological intensification in agronomy: revisiting methods, concepts and knowledge.European Journal of Agronomy.34:197-210.

Drowns B., L. Robert and M. Lawrence. (1991). Meta-Analysis in Educational Research.p:1-5. https://eric.ed.gov/?id=ED339748

Educational Researche.1(5):24-38.

Faraj, A. (2002). Meta- Analysis as a Research Method in the Field of Libraries and Information Science. Intellectual Production in the Subject of Researchers Orientation towards Open Access. Arabic Studies in Libraries and 
Information Science.14(1): pp 80- 89. https://zenodo.org/ record/ 570067\# . X2oMWfnXLIU

Fisher, M. (2015). Moving science through: Meta-analysis.CSA News.USA:60:4-6.

Gerstner, K., D. Moreno-Mateos, J. Gurevitch, M. Beckmann, S. Kambach and H.P. Jones. (2017). Will your paper be used in a meta-analysis? Make the reach of your research broader and longer lasting. Methods Ecol. Evol. 8:777-784. https://doi.org/10.1111/2041-210X.12758.

Glass, G. (1982). Meta -Analysis: An Approach to the Synthesis of Research Results. Journal of research in science teaching .19:93-112.

Gogtary, N. and U. thatte. (2017). An Introduction to Meta-Analysis. journal of the association of physicians of india . vol. 65.pp:78-85.

Gozza, M., S. Peter and S. Smith (2012) Learning presence: Additional research on a new conceptual element within the Community of Inquiry (CoI) framework. The Internet and Higher Education.15(2): 89-95.

Hassan, S.M. (2005). Indicators of Meta- Analysis for Researches of Self Efficacy in Light of Bandura Theory. King Saud University. College of Education Research Center. P:87.

Hedges, L.V. and I. Olkin,. (1985).Statistical Methods for Meta-Analysis. Academic Press, New York.PP:369. https://www.jstor.org/stable/177062.

Hedges, L.V., J. Gurevitch, and P.S. Curtis. (1999). The meta-analysis of response ratios in experimental ecology. Ecology, 80:1150-1156.

Herzmann, D.E., L.J. Abendroth, and L.D. Bunderson. (2014). Data management approach to multidisciplinary agricultural research and syntheses. Journal of soil and water conservation. 69:180185A.

Hjorland, B. (2002). Meta- analysis should also be visible inside information science. Journal of the american Society for Information Science \& Technology. 53(4): 324 .

https://acsess.onlinelibrary.wiley.com/doi/full/10.2134/csa2015-60-5-1.

https://doi.org/10.5465/amj.2013.0319

https://www.fdacs.gov/content/download/76315/file/NC1_FinalReport.

Hunt, L.A., J.W. White and G. Hoogenboom. (2001). Agronomic data: Advances in documentation and protocols for exchange and use. Agricultural Systems. 70:477-492.

Hunter, J.E., F.L. Schmidt and G.B. Jackson. (1982). Meta-analysis: Cumulating research findings across studies. Beverly Hills, CA: Sage.PP:1017-1064. https://www.researchgate.net/publication/275414777

Jackson, S.E. (1984). Can meta-analysis be used for theory development in organizational psychology? Paper presented at the annual meetings of the American Psychological Association, August, Toronto, Ontario.407-442.

Jeery, J. V and L. B. Shelby. (2008). Understanding Meta-Analysis: A Review of the Methodological Literature. Leisure Sciences,30: 96-110. https://doi.org/10.1080/01490400701881366 
Knapp, S., G.A. Marcei and V.D. Heijden. (2018). A global meta-analysis of yield stability in organic and conservation agriculture. Nature Communications. 9, Article number: 3632 pp:1-10. https://www.nature.com/articles/s41467-01805956-1

Lauren, C. P, K. M. Leithen, C. M. Kevi, p. Jenny ,V. Perry and C. Kremen. (2015). Diversification practices reduce organic to conventional yield gap. Proc. R. Soc. Lond. B: Biol. Sci. 12(6):1-7.. https://doi.org/10.1098/rspb.2014.1396

Lin, C. S., M. R. Binns and L.P. Lefkovitch. (1986). Stability analysis: where do we stand? Crop Sci. 26, 894-900.

Manssfield, R. and V. Busse (1077) Meta-Analysis of Research: A Rejoinder to Glass.

Matarazzo, B., and P. Nijkamp. (1997). Methodological complexity in the use of metaanalysis for empirical environmental case studies. International journal of social economics. 34(719): 799-811.

Moher D, L. Shamseer, M . Clarke, D. Ghersi, A . Liberati, M. Petticrew, P. Shekelle and L.Stewart.(2015). Preferred Reporting Items for Systematic Review and Meta-Analysis Protocols (PRISMA-P) (2015). statement. Systematic Reviews; 4:1-25.

Morrison ,H. (2006). Evidence-based librarianship and open access. Evidence BasedLibrary and In- formation Practice. 1(2): 46-50.

Oltmer, K.,N. Peter,F. Raymond and B. Floor (2000). A Meta-Analysis of Environmental Impacts of Agri-Environmental Policies in the European Union Tinbergen Institute Discussion Paper.83(3):1-24.

Pittelkow,M., X. Liang, A. Bruce, K. Groenigen, J. Lee, E. Mark, N. Gestel, J. Six, and C. Kessel. (2015). Productivity Limits And Potentials Of The Principles Of Conservation Agriculture, 365-368. https://www.nature.com/articles/nature13809

Raja, A. (2004). Research Methodology in Psychological and Educational Sciences. Fourth Edition. Cairo. Publishing house for universities.PP:326.

R-DTU. (2009). Meta-Analysis on Grain Yield Effects of Cereals-Legume Intercropping. Ensai, Denmark.pp:47. .

Richard A. G, E.Susan. and A. Raymond. (1987). Meta -Analysis. Research in Organizational Behavior, 9(1): 407-442.

Sacha, W.R. and A.M. Bilton. (2018). Agricultural Technology in the Developing Word : A Meta- Analysis of the a doption literature, The American Society of mechanical engineers.pp:12. https://www.asme.org/

Salim, M., F. F. Al Mutairi. (2005). Cultural Content in Arabic Language Books for Non- Arabic older Native Speakers (Meta- Analysis). Fifth International Conference for Arabic Language. PP.160-178.

Saxton, M. L. (2008) Meta-analysis in library and information science method, history. And recommendations for reporting research. Library Trends (2006). Aailable at: http://www.encyclopedia.com/doc/IGI-151440810. html. accessedat . 
Seufert, V.,N. Ramankutty and J. Foley. (2012). Comparing The Yields Of Organic And Conventional Agriculture, 229-232.

Shaddish, W.R. and C.K. Haddock (1994). Combining Estimates Of Effect Sizes. In: H. Cooper and L.V. Hedges (eds) The Hand book of Research Synthesis. Russel Sage Foundation, New York, 261-281.

Tilman, D., P. B Reich and J. M. Knops (2006). Biodiversity and Ecosystem Stability In A Decade-Long Grassland Experiment, 629-632.

Timothy, J. and J. Andersson (2019). Does Size Matter? A Critical Review of MetaAnalysis In Agronomy.PP:201-229. https://doi.org/10.1017/ S001447971 $\underline{9000012}$

Winston, M. D. (2007). Ethical leadership a dethical decision making: A meta-analysis of research related to ethics education. Library \& Information Science Research. 29(2): 230-251.

Yousif, N. M. (1993). Meta- Analysis as a Follow up method of the Psychological researches Results. Al- Masriyya Journal for Evaluation and Standardization..4(2):54-63. 